\title{
First Year Students Understanding Of Elementary Concepts In Differential Calculus In A Computer Laboratory Teaching Environment
}

K. Naidoo, (E-mail: kristieN@dut.ac.za), Durban University, South Africa R. Naidoo, (E-mail: naidoor@dut.ac.za), Durban University, South Africa

\begin{abstract}
This paper focuses on blended learning in mathematics I module in elementary calculus, at a University of Technology. A computer laboratory was used to create a learning environment that promoted interactive learning together with traditional teaching. The interactive learning was performed using projects to optimize the discovery and error diagnosis in an elementary differential calculus class consisting of first year engineering students. A group of 33 engineering students (the experimental group) completed a project in elementary calculus as part of their course requirement for the mathematics I module in the engineering faculty. The project was designed to support the development of the differential calculus frames "limit of a sequence", "average rate of change" and "instantaneous rate of change". Students were clinically interviewed on their tasks in the project. We also compared a control group of students (randomly selected students) in a completely traditional to the experimental group. Both groups were subjected to the Orton's test on differential calculus. Analysis of project work indicated that students have developed specific mathematical mental frames in elementary calculus. The control group exhibited more structural and executive errors than the experimental group. The experimental group tended to describe the concepts using deep structures than surface structures. Statistically the scores on the Orton's tests indicated a clear difference between the experimental group and the control group. We can suggest blended learning enhances understanding of key concepts in elementary calculus.
\end{abstract}

\section{INTRODUCTION}

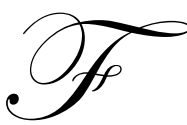

ist year mathematics courses at a University of Technology consist of basic mathematics and calculus. The calculus component forms a major section of first year mathematics course. Much emphasis in the calculus is placed on differentiation. Differential calculus is fundamental to further study of mathematics for engineering at a University of Technology. Courses in Integration, ODE's, PDE's, Laplace Transforms, Numerical mathematics and Mathematics Modelling all have their roots in the understanding of elementary concepts in calculus.

At many SAMS (South African Mathematics Society) conferences mathematicians at Higher Institutions state that students have a mechanistic perspective of the derivative. Tall (1997) refers to students developing coping strategies, like computational and manipulative skills, when they are faced with conceptual difficulties.

At the University of Technology mathematics is not required as a specialization. Mathematics is used as a tool for the engineering courses. Since mathematics is not a specialist subject students spend little time to study of mathematics. This adds to lack of appreciation and understanding of differentiation. Large class sizes contribute to the weak preparation and disinterest in the subject. Students resort to techniques that will help them to pass. These 
include drill and manipulative approaches. Students are rarely engaged in problems that involve "insight'. The time allocated for the teaching also does not allow for teaching for understanding.

We concur with Smith \& Moore (1991):

Much of what our students have actually learned .........more precisely, what they have invented for themselves is a set of 'coping skills' for getting past the next assignment, the next quiz, the next exam. When their coping skills fail them, they invent new ones. The new ones don't have to be consistent with the old ones; the challenge is to guess right among the available options and not get faked out by the teacher's tricky questions....... We see some of the 'best' students in the country; what makes them 'best' is that their coping skills have worked better than most for getting them past the various testing barriers by which we sort students. We can assure you that that does not necessarily mean our students have any real advantage in terms of understanding mathematics.

This phenomenon was also observed by Morgan (1990) in England. His research revealed that students had problems in the:

- $\quad$ understanding the meaning of the derivative when it appeared as a fraction or the sum of two parts

- $\quad$ application of the chain rule for differentiation

- $\quad$ choice of the parameters when doing partial differentiation

- $\quad$ procedures for solving maxima and minima problems.

Hughes-Hallet (1989) indicated in her study that students can differentiate complicated functions analytically but cannot interpret differentiation graphically. Students need to learn through discovery, visualisation and experimentation.

Orton (1983) in his investigation on the understanding of differentiation by students at high school and training college students concluded that "both groups found the same items difficult and the same items easy". He concluded that students had little intuitive understanding as well as fundamental misconceptions about the derivative.

Cipra (1988) and White (1996) in their study show that students enrolled in the traditional university calculus class have a very superficial and incomplete understanding of many of the basic concepts in calculus. This was attributed to the rote and manipulative learning that takes place in an introductory course.

Ferrini-Mundy (1998) described students understanding of mathematics as a static collection of concepts and skills that need to be mastered one by one. Students do not see mathematics as a core course for their career. At the University of Technology, in particular, in the Faculty of Engineering, mathematics is regarded as a service course. Mathematics I for engineering students is a semester course.

The need for alternate methods of instruction to enhance teaching and understanding of calculus is essential. The University of South Australia redesigned the first year engineering mathematics course to be aligned it to qualities that graduates had to demonstrate in terms of that specified by The Institute of Engineers, Australia. (Colgan: 2000)

The syllabus and teaching methodology of the first year mathematics subjects had to include:

- $\quad$ innovations based on information technology;

- $\quad$ opportunities for problem-based group work;

- $\quad$ opportunities for students to undertake self-learning of material deliberately not covered in lectures;

- $\quad$ a mixture of supervised and unsupervised learning activities;

- $\quad$ alternative pathways for students with less than a predetermined minimum prior knowledge Colgan (2000).

Calculus forms $40 \%$ of the Algebra component of the grade twelve national examinations in South Africa. This contributes to at least $20 \%$ of the overall mathematics examination. 
Tall (1992) identifies some difficulties that students encounter with calculus. These include:

- $\quad$ algebraic manipulation or lack of it;

- $\quad$ preference for procedural methods rather than conceptual understanding;

- $\quad$ difficulty in translating real-world problems into calculus formulation;

- $\quad$ restricted mental images of functions

- $\quad$ difficulty in absorbing complex new ideas in limited time

- $\quad$ difficulty with notation

Currently much of the focus in mathematics at secondary school is based on wanting to make mathematics simpler as far as possible. Boaler (1995) in her research refers: Mathematics lessons at Amber Hill were algorithmic, focussing on standard methods, rules and procedures.” A similar situation exists in mathematics learning environments in a majority of situations. Little or no attention is given to understanding.

Researchers generally concur that calculus courses at Grade 12 level are pretty much freewheeling - they emphasize the mechanical techniques to the extent that drill is necessary and they contain certain illustrations and applications that the educator is competent to explain and the learners ready to receive. Student preparation is a key factor to how understanding unfolds itself. This trend, from my experience at secondary school, is brought to tertiary level from students' previous learning experience. Lecturers too tend to perpetuate this type of teaching.

This means that students know less and less about calculus because they are given less and less preparation, and in fact, progressively worse preparation, in high schools. This factor also comes into play when one looks at errors made in elementary calculus during first-year University of Technology level.

Naidoo (1996) deduced that first year mathematics students study by rules. They do not enjoy mathematics and are de-motivated. Lecturers tend to teach mechanistically and do standard type solutions to standard type problems. He draws attention to the fact that mathematics at Technikon level is not a specialist subject. This contributes to the "poor" understanding of critical concepts that are essential for extended learning - a type of understanding that is needed to support an increasingly technological world. Consequently the time and attention given to study mathematics is limited. This contributes to failure in making a distinction between process and the concepts integral to the process. Hence integrating mathematics into the engineering discipline becomes plausible. The learning of mathematics must not be reduced to isolated situations. Society needs solutions to daily problems and these rely heavily on mathematical support.

In this study we determine how the understanding of a class of students using particular pedagogy (blended learning) similar or different from those in a class using different pedagogical strategies (traditional learning)

\section{THEORY AND LABORATORY METHOD}

Davis (1984) raises an important concern:

If a person wants to learn certain mathematics, we are less inclined to accept the verdict that he or she cannot do so. We want more specific information; we want to know exactly what obstacles impedes this person's progress, exactly what they cannot seem to do, exactly what errors they are making and why they make them.

Errors in student's understanding of differentiation are characterized as structural, executive and arbitrary by Donaldson (1963). The structural error is defined as when the student fails to create mental relationships. The executive error is a failure to carry out manipulations and arbitrary errors are those in which the students behave arbitrarily and fail to take into account constraints.

Marton, Entwistle and Ramsden note the importance of group work and problem-solving as a means of fostering the deep approach to learning. These are synonymous to the "active learning”, "cooperative learning" and problem-based instruction”. 
Surface learning focuses on comprehension and reproduction of knowledge (rote learning). Rhem (1997) mentions the characteristics of courses that incline students to a surface approach:

- $\quad$ excessive amount of material in the curriculum

- $\quad$ high class contact hours

- $\quad$ excessive amount of course material

- $\quad$ lack of opportunity to pursue subject in depth

Ramsden (1999) found that Mathematica gave more power plus explicitness. It gave opportunity to set up sophisticated models in a way that students understood them and they were able to set up their own projects. Computers can be used to define functions and determine their domain. By using scaling we can find limits and the derivative.

Some advantages of lecturing using computers as cited by Cotton (1995):

- $\quad$ encourages shy learners to build confidence;

- $\quad$ each learner would be allowed to work independently at their own pace;

- $\quad$ arouses learners through active participation;

Further advantages of lecturing using computers include:

- $\quad$ as the learner is in involved in the activity at hand attention span is improved;

- $\quad$ long-term memory is enhanced by the fact that the learner takes a personal stake in getting through the steps that are required to succeed;

- $\quad$ students that are engaged in activity are motivated;

- focus is on individual attention: learner is able to ask tutor for assistance with any computer jargon (like syntax errors);

- $\quad$ stimulation of cognitive drive; and

- $\quad$ improves self enhancement and affiliation.

Tall (1996) used the "local straightness" of the graph as his "good" cognitive root to build calculus. His Graphic Calculus software enabled the student to magnify a portion of the graph to observe the straightness by tracing the gradient numerically along the graph. Additional software allowed the student to point the mouse at a given place in the plane and draw a line segment of the given gradient. An approximate solution could be constructed physically and visually by sticking segments from end to end. This is a means of encouraging deep approaches to learning. The student is motivated further by adding reality to his solution. In this way his meaning can be extended to real-world problems that society needs solution to.

Disadvantages of lecturing using computers include:

- $\quad$ some knowledge of working in a computer environment is necessary;

- $\quad$ knowledge of syntax in Mathematica (or other software) is an essential tool.

- $\quad$ resources needed have financial implications

According to Vital (2004) projects or project work form a "progressive" approach to mathematics education and advocates more "open-ended", "problem-centered" activities in which learners are given greater independence in their learning, in contexts relevant to them. In terms of the outcomes based approach to learning project work is extensively used as an assessment strategy in modern South African Schools. Not much research exists to test effect and use of project work. In countries like Scandinavia and Denmark project work had been introduced for decades. 
Dubinski (1996) developed a framework for research and curriculum development in mathematics that he calls the Action-Process-Object-Schema (APOS) theoretical perspective. Students seeing a concept for the first time are limited to an action conception of that concept. For example, beginning calculus students may understand differentiation as an action on polynomials, in which rules are applied in sequence. As the student reflects upon a particular action, he/she begins to view the concept as a process. In the case of differentiation, the student would understand that it is a more general process, not limited to a set of rules applied to individual functions. In the computer laboratory environment the student is offered the graphical approach to understanding the derivative.

Clearly traditional methods do not focus on real world problems. This accounts for the shortcoming in students' ability to think in realistic situations and inhibits their ability to design their own solutions. The discovery approach and students learning at their own pace becomes necessary.

De Ting Wu (2004), found that the limit concept was confusing to students. Task group meetings at "The 9th International Congress on Mathematical Education (ICME) in Japan in 2000" and "The 10th ICME in Denmark in 2004," revealed to the participants that while the teaching and learning of the limit concept continues to be a muchdiscussed topic, it is also a topic that is both important and difficult.

Different thinking and study methods are needed for the advancement from elementary mathematics. Secondary school learners lack background to advanced mathematics and hence the understanding the limit concept. The limit concept in calculus is one of the most critical points for teaching and learning. meetings revealed to the participants that while the teaching and learning of the limit concept continues to be a much-discussed topic, it is also a topic that is both important and difficult. Students need new approaches and powerful tools to help them to overcome the difficulty in studying limit concepts and to realize a smoother transition from their secondary mathematics education to learning a more advanced level of post-secondary mathematics.

De Ting Wu advocates that computer technology is a powerful tool and a helpful aid in teaching and learning mathematics. Its components: computation, visualization, and animation could be helpful in developing new approaches to the teaching of the limit concept and ultimately to help students to overcome their difficulty in understanding this important concept.

Zandieh (2000), views the concept of the derivative as ratio, function and limit as process-object pairs. These layers can be viewed as dynamic processes and as static objects. When a student lacks a structural conception of one of the layers the pseudo-structural term is used to describe an object with no internal structure.

The graphic interpretation of the derivative is seen in three layers viz the slope of the secant line, limit of the sequence of slope values of secant lines and the instantaneous slope (limit).

\section{METHODOLOGY}

A group of 33 students from the chemical engineering department participated in this study (experimental group).. Students were orientated to the mathematica software during four two hourly sessions weekly at the mathematics laboratory at the University of Technology. Students then completed a project task using mathematica software. The responses from the project work constituted the first set of data.

Students had to perform the task in groups at the mathematics laboratory using Mathematica tasks. (See APPENDIX:1). The aim of the tasks was to assist students to understand the elementary concepts in calculus. The task also contributed to their part assessment for the mathematics module MATH101. This would also ensure that the participants would carry out the project tasks meaningfully.

Task 1, tested the understanding of the limit of a sequence. Students were exposed to the limit from the left, the graphical solution of functions and ratios using Mathematica would give them an indication that the sequence converged to a particular point. The numerical solution would identify the converging point. 
In Task 2, the student had to use the frame "function", "change of function", "ratios", "average rate of change" and "slopes" (ratios) to solve this problem. The frame "straight line" had to be used to obtain the equation of the secant line. A visual representation of the graphs would enable students to see, that as the interval between the corresponding $\mathrm{x}$ - values were made smaller, the secants approached a tangent.

Task 3 required the students to retrieve the frames tangent lines and rates of change.of secant lines. Students would have to apply the fact the instantaneous rate of change is the limit of the average rate of change of a function $\mathrm{f}$ as the width of the interval $\mathrm{x}$ tends to zero. The frame

$\lim _{h \rightarrow 0} \frac{f(0.5+h)-f(0.5)}{h}$ had to be retrieved.

We further used a modified Orton's test [1983] to elicit responses from a control (traditional teaching group) and the experimental group. Table 1 below exhibits the modified Orton's test.

Table 1: Items And Item Description

\begin{tabular}{|c|c|}
\hline Item No & Item Description \\
\hline 1 & Infinite geometric sequences \\
\hline 2 & Limits of geometric sequence \\
\hline 3 & Rate of change from straight line graph \\
\hline 4 & Rate, average rate and instantaneous rate \\
\hline 5 & Average rate of change from curve \\
\hline 6 & Carrying out differentiation \\
\hline 7 & Differentiation as a limit \\
\hline 8 & Use of $\delta$ - symbolism \\
\hline 9 & Significance of rates of change from differentiation \\
\hline
\end{tabular}

The modification included the function, change in the function, average rate of change, instantaneous rate of change and connected the two ratios, average and instantaneous rate of change by the limit concept.

It is clear from the table 1 that our method is similar to Zandieh (2000) who uses ratio, a limit and a function etc. for the interrogation of the data .The Orton testing tool suit students from Engineering as they are taught explicitly limits as a converging sequence converging to a point., average rate of change and instantaneous rate of change as a derivative.

Experimental group were interviewed on their project tasks output. Analysis for deep, intermediate and surface learning was performed on the data from the project tasks. Error analysis performed on the data gleaned from the experimental and control groups using Orton's modified test.

\section{ANALYSIS OF DATA}

The data consisted of student project protocols. Exemplars are cited in Appendix 2.

Below in Table 2 responses were categorized as deep, intermediate and surface using specific criteria:

Table 2: Analysis Of Deep And Surface Learning

\begin{tabular}{|c|c|c|c|}
\hline Project Task & Deep & Intermediate & Surface \\
\hline 1 & 8 & 4 & 6 \\
\hline 2 & 9 & 5 & 4 \\
\hline 3 & 8 & 6 & 4 \\
\hline
\end{tabular}




\section{Task 1 was based on the convergence of a sequence and the limit concept.}

Deep: Responses must include "sequences", “converges to a point" and "limit". Intermediate: Responses must include "sequences", and "converges to a point” but neglects the "limit" Surface: Responses have "sequences" but does not mention convergence.

(See appendix 3 Exemplar for student S1 Task 1)

\section{Task 2 was based on the average rate of change.}

Deep: Responses includes "function", "change in function $(f(x+\Delta x)-f(x)$ ", "points $(x, y)$ and $(x+\Delta x, y+\Delta y)$ on the graph and represents a secant line"

Intermediate: Responses includes "function", "change in function $(f(x+\Delta x)-f(x)$ " but does not mention a secant line.

Surface: Does mention change in function, not able to indicate points $(x, y)$ and $(x+\Delta x, y+\Delta y)$ on the graph and show that it represents a secant line"

(See appendix 3 Exemplar for student S5 Task 2 )

\section{Task 3 was based on instantaneous rate of change.}

Deep: Able to show "sequence of secants converge to a point to a tangent", and "slopes of secants converging to a

slope of the tangent”, and “ $\frac{d y}{d x}=\lim _{\Delta x \rightarrow 0} \frac{\Delta y}{\Delta x}$ ”, $\frac{d y}{d x}$ is the slope of the tangent and instantaneous rate of change, and $\frac{\Delta y}{\Delta x}$ is the average rate of change which is the slope of the secants.

Intermediate: Able to show "sequence of secants converge to a point to a tangent", and "slopes of secants converging

to a slope of the tangent” but not responses to and " $\frac{d y}{d x}=\lim _{\Delta x \rightarrow 0} \frac{\Delta y}{\Delta x}$ ”, $\frac{d y}{d x}$ is the slope of the tangent and

instantaneous rate of change, and $\frac{\Delta y}{\Delta x}$ is the average rate of change which is the slope of the secants.

Surface: No distinction made between slopes of secants and tangents.

(See appendix 3 Exemplar for student S8 Task 3)

The tables that follow show a classification of the errors made by the Experimental and Control Group. 
Table 3: Classification of Errors - Experimental Group

\begin{tabular}{|l|c|c|c|}
\hline \multicolumn{1}{|c|}{ Classification Of Items } & Structural Errors & Executive Errors & Arbitrary Errors \\
\hline Sequence & 26 & 0 & 2 \\
\hline Limit & 19 & 0 & 13 \\
\hline Average rate of change & 8 & 1 & 0 \\
\hline Rate of change & 16 & 0 & 0 \\
\hline Derivative & 4 & 9 & 0 \\
\hline Symbolism & 4 & 0 & 0 \\
\hline
\end{tabular}

Table 4: Classification of Errors - Control Group

\begin{tabular}{|l|c|c|c|}
\hline \multicolumn{1}{|c|}{ Classification Of Items } & Structural Errors & Executive Errors & Arbitrary Errors \\
\hline Sequence & 32 & 0 & 0 \\
\hline Limit & 27 & 0 & 0 \\
\hline Average rate of change & 24 & 1 & 0 \\
\hline Rate of change & 27 & 1 & 0 \\
\hline Derivative & 11 & 11 & 0 \\
\hline Symbolism & 11 & 0 & 0 \\
\hline
\end{tabular}

The experimental group made fewer structural errors and executive errors than the control group. A graphical representation of the overall scores is given below:

\section{Overall Scores Using Orton's Tests}

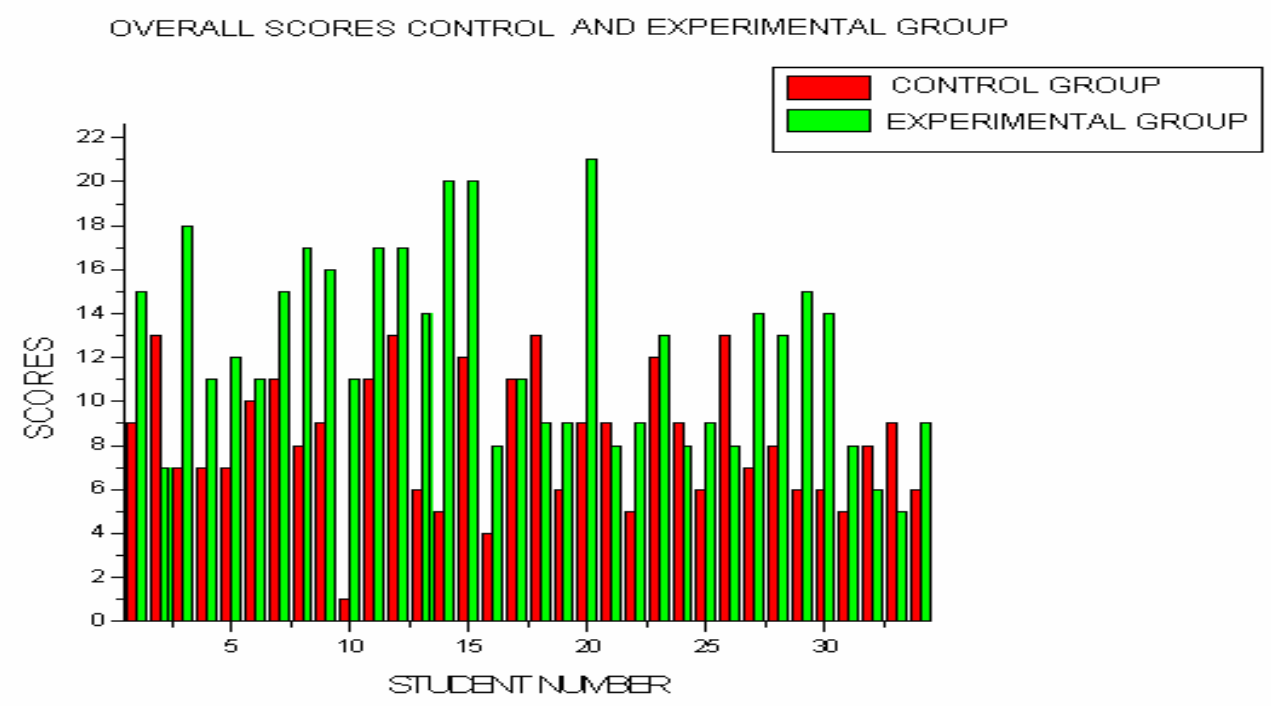

The graph shows a clearly distinction in the improved learning of the experimental group as compared to the control group. The overall performance of the experimental group was enhanced by their use of the computer in their teaching and learning of differential calculus concepts. It is apparent that students who used the computer to perform tasks for their compulsory project had an advantage of using constructive interactive methods and co-operative learning strategies to aid their understanding of concepts. 
However both groups struggled with the items presented to them. Five notable peaks in the graphical representation show that the experimental group had an advantage over the control group. Their experience in their project work using the computer assisted them in their responses to the paper and pencil task presented to all the students. Some students in the experimentaxl group had no previous experience in working with computers.

\section{APPENDIX 1}

\section{Task 1}

Find the limit of the following numerically and graphically. Discuss your results. For the numerical values show explicitly the sequence is converging or diverging.

$\lim _{x \rightarrow 4} \frac{2-\sqrt{x}}{4-x}$

Task 2

Let $f(x)=3 x-2 x^{2}$

2.1 Find the average rate of change of $\mathrm{f}$ from $\mathrm{x}=0.5$ to $\mathrm{x}=0.9$

$2.2 \quad$ Find the equation of the corresponding secant line.

2.3 Plot the graphs of $\mathrm{f}$ and the secant line on the same axes.

2.4 Repeat parts 2.1 to 2.3 for $\mathrm{x}=0.5$ and $\mathrm{x}=0.51$. Explain what you observe.

2.5 Zoom in on the graph around the point $(0.5 ; \mathrm{f}(0.5))$. Show your plot and explain what you observe about the two graphs in 2.4

2.6 Re-plot the graph $f$ over the interval [0; 1$]$. Now zoom in on the graph around the point $(0.5 ; f(0.5)$ until the graph looks like a straight line. Show your plot and explain how you can use this graph to estimate the slope of this line. (Hint: Move the mouse pointer to the line and click at two different points on it; then observe the first and second coordinates of the points you clicked on.)

\section{Task 3}

Let $f(x)=3 x-2 x^{2}$

3.1 Find the instantaneous rate of change of $\mathrm{f}$ at $\mathrm{x}=0.5$ using the definition of the derivative.

3.2 Find the equation of the corresponding tangent line.

3.3 Plot the graphs of $\mathrm{f}$ and the tangent line on the same system of axes. Zoom in on the graph around the point $(0.5 ; \mathrm{f}(0.5))$ until the two graphs are indistinguishable. How close did you have to get?

3.4 Plot the graph of $\underline{\mathrm{f}(0.5+\mathrm{h})-\mathrm{f}(0.5)}$.

$\mathrm{h}$

Explain how you can use this graph to estimate the derivative of $f$ at 0.5 . 


\section{APPENDIX 2: EXPERIMENTAL GROUP PROJECT}

Here we exhibit suitable exemplars from a student response in the project.

Task A: Finding the limit graphically and verifying numerically:

Mathematica command: Mathematica graphical solution:

Plot $[F[x],\{x, 0,3.99\}]$

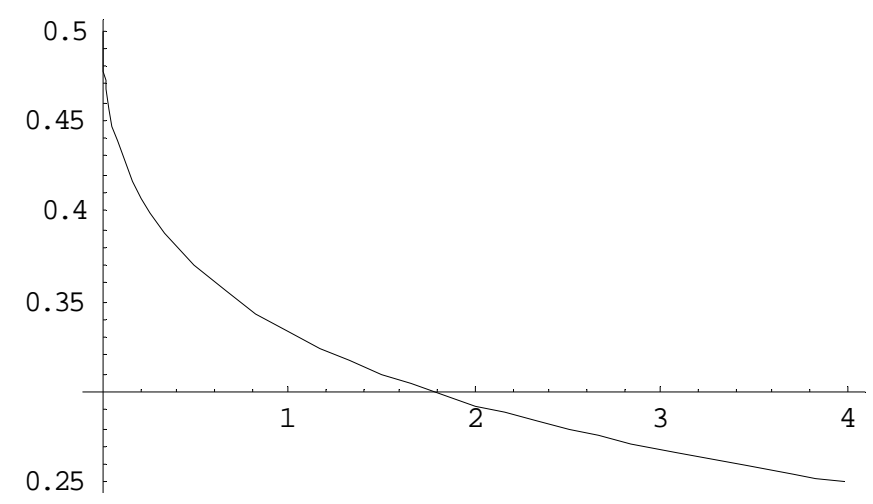

\{The student determines left hand limit graphically by deducing as $x \rightarrow 4^{-}$(from the left)

$\left.f(x) \rightarrow f\left(4^{-}\right) \rightarrow 0.25\right\}$

Mathematica command:

$\operatorname{Table}[N[\{x, f[x]\}],\{x, 1,3.99,0.1\}] / /$ Table Form

Mathematica numerical solution:

$\begin{array}{llll}1 . & 0.333333 & 2.6 & 0.27682 \\ 1.1 & 0.327997 & 2.7 & 0.274486 \\ 1.2 & 0.323055 & 2.8 & 0.272233 \\ 1.3 & 0.318454 & 2.9 & 0.270056 \\ 1.4 & 0.314148 & 3 . & 0.267949 \\ 1.5 & 0.310102 & 3.1 & 0.265909 \\ 1.6 & 0.306287 & 3.2 & 0.263932 \\ 1.7 & 0.302678 & 3.3 & 0.262014 \\ 1.8 & 0.299254 & 3.4 & 0.260152 \\ 1.9 & 0.295998 & 3.5 & 0.258343 \\ 2 . & 0.292893 & 3.6 & 0.256584 \\ 2.1 & 0.289928 & 3.7 & 0.254872 \\ 2.2 & 0.287089 & 3.8 & 0.253206 \\ 2.3 & 0.284368 & 3.9 & 0.251582 \\ 2.4 & 0.281754 & & \\ 2.5 & 0.279241 & & \end{array}$


\{Student finds the left hand limit numerically by viewing the converging sequence and concludes that

As $x \rightarrow 4^{-}$(from the left) $\left.f(x) \rightarrow f\left(4^{-}\right) \rightarrow 0.25\right\}$

\section{Mathematica command:}

Plot $[F[x],\{x, 4.0001,5\}]$

Mathematica graphical solution:

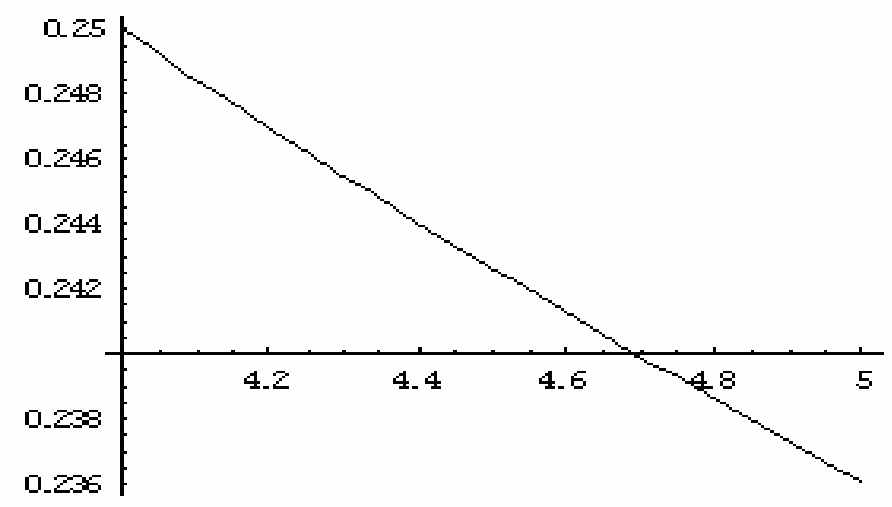

\{Student plots graph and finds limit from the right and deduces that. as $x \rightarrow 4^{+}$(from the right)

$$
\left.f(x) \rightarrow f\left(4^{+}\right) \rightarrow 0.25\right\}
$$

\section{Table $[N[\{x, F[x]\}],\{x, 4.001,5,0.1\}] / /$ Table Form}

\section{Mathematica numerical solution:}
4.001
0.249984
4.101
0.248441
4.201
0.246936
4.301
0.245466
4.401
0.24403
4.501
0.242627
4.601
0.241255
4.701
0.239913
4.801
0.2386
4.901
0.237314

\{Student finds the right $t$ hand limit numerically by viewing the converging sequence and concludes that 
As $x \rightarrow 4^{+}$(from the right) $\left.\quad f(x) \rightarrow f\left(4^{+}\right) \rightarrow 0.25\right\}$

Task B: Finding average rate of change:

$F[x]: 3 x-2 x^{2}$

$f[0.5]) / 0.4$ \{student finds gradient of the secant line from $f(0.9)$ to $f(0.5)$ with increment $h=0.4$ with slope $=0.2\}$

$=0.2$

To view the function and the secant line on the same system of axes the following commands were performed:

Equation of a secant line

$y=m x+c$ [straight line $]$

\{Since the gradient is calculated above the intercept is calculated using the solve command\}

Solve $[f[0.9]==0.2 * 0.9+c, c]$

$\{\{c=0.9\}\} \quad\{$ Student calculates the value of $c\}$

Graph of secant line $y=0.2 x+0.9 \quad$ \{equation of secant line obtained

To plot secant and initial function on same axes

$L\left[x_{\_}\right]:=0.2 x+0.9[$ secant line equation $]$

$f\left[x_{-}\right]:=3 x-2 x^{2}$ [original function]

$\mathrm{S}\left[\mathrm{x}_{-}\right]:=0.9 \quad 8 \mathrm{x}+0.51$ student finds of the secant line from $f(0.5)$ to $f(0.51)$ with increment $h=0.01$ with slope $=0.98\}$

Plot $[\{f[x], L[x], S[x]\},\{x, 0.4,1.0\}]$

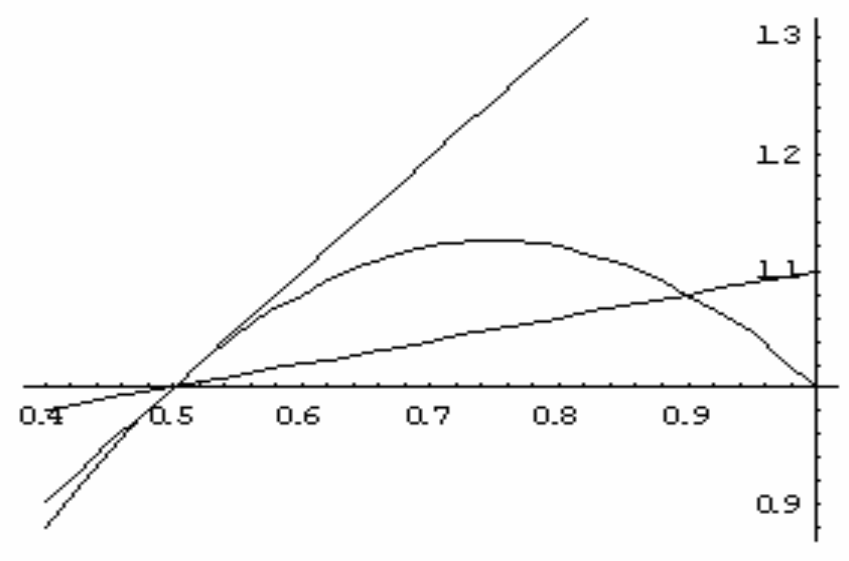




\section{Task C: Find instantaneous rate of change:}

$F\left[x \_\right]:=3 x-2 x^{2}$

Limit $[(F[0.5+h]-F[0.5]) / h, h=0]$ \{the definition of the derivative is used, $\left.\frac{d y}{d x}=\lim _{h \rightarrow 0} \frac{f(x+h)-f(x)}{h}\right\}$

Solve $[F[0.5]=0.5+c, c]$ \{Calculates the $y$ intercept for the equation of the secant at

$x=0.5\}$

\section{Mathematica solution:}

$\{\{c=0.5\}\}$

$G\left[x_{-}\right]:=x+0.5$

Plot $[\{F[x], G[x]\},\{x, 0,1\}]$ PPlots the graphs of the function and the secant on the same system of axes $\}$

\section{Mathematica graphical solution:}

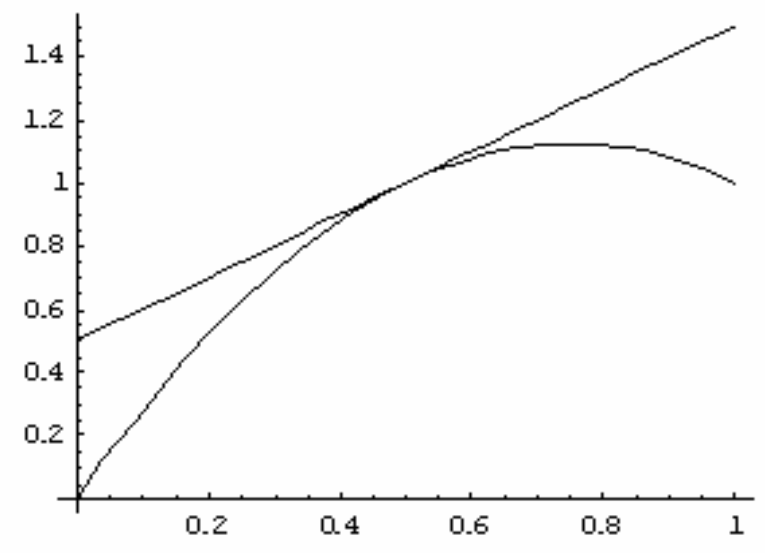

\section{Mathematica command:}

Plot $[\{F[x], G[x]\},\{x, 0.49,0.51\}]$ Zooming into a small section of the graph indicating that tangent and curve coincides $\}$ 


\section{Mathematica graphical solution:}

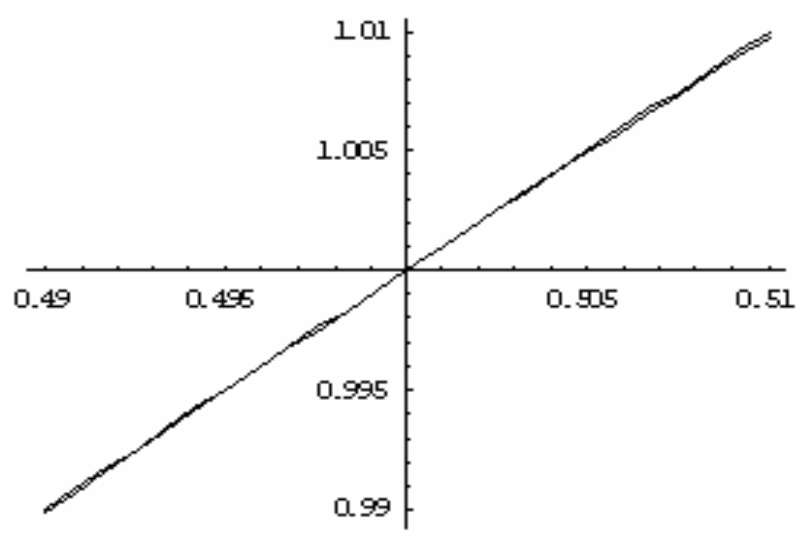

\{Over a smaller domain, the secant within the region of the domain becomes a tangent\}

\section{APPENDIX 3: EXEMPLARS FROM STUDENT INTERVEWS}

\section{Exemplar for student S1 Task 1:}

I: $\quad$ Explain your results (output) obtained for question 1.

S1 "I plot the graph and found the limit from the left and verified this by showing that the sequence converges at 0.25 by getting the numerical solution as well."

I: What happens at 0.25 ?

S1: $\quad$ The sequence converges.

\{student response does not connect the limit concept to convergence\}

I: $\quad$ Explain in your own words what this means?

S1: It means that the limit exists and the point to which the sequence converges is the limit of the sequence.

\section{\{deep structure response\}}

\section{Exemplar for student S5 Task 2:}

\section{I: $\quad$ Explain your output for Task 2 .}

S5: We were asked to find the average rate of change.

I: $\quad$ Tell me what you did to get the average rate of change?

S5: I found the difference in the function over a small interval and plotted the graph. 
I: Why did you plot the graph?

S5: I wanted to get a visual representation.

\{intermediate structure response - no mention of secant line\}

\section{Exemplar for student S8 Task 3:}

I: $\quad$ Explain your output for Task 3.

S8: I wanted to calculate the instantaneous rate of change at $\mathrm{x}=0.5$

I: $\quad$ Explain what you did?

S8: I plotted the graph of the tangent and curve at observed what happened at 0.5

\{surface response - repeated features of the question\}

\section{REFERENCES}

1. Boaler, J. (1997). Experiencing School Mathematics: Teaching styles, sex and setting. Buckingham: Open University.

2. Colgan, L., (2000). MATHLAB in first-year engineering mathematics. International Journal of Mathematics Education in Science and Technology, 31(1), 15-25.

3. Davis, R.B., (1984). Learning Mathematics: The Cognitive Science Approach to Learning Mathematics. Croom Helm Ltd.

4. De Ting Wu. (2004) Teaching the Limit Concept in Calculus with Technology. A Proposal to the ASC Technology Centre Interactive. Available online at: http://www.colleges.org/techcentre/fellowships/grants/Fellows06/de_ting_Wu.pdf. (Accessed 30 September 2004).

5. $\quad$ Donaldson, M. (1984). A study of children's thinking. London, Tavistock Publications.

6. Dubinsky, E., (1991). Reflective Abstraction in Advanced Mathematical Thinking. In D.O. Tall (ed.). Advanced Mathematical Thinking, Kluwer, Dordrecht, 95-123.

7. Hughes Hallet, D., (1991). Visualisation and Calculus Reform. In W. Zimmerman \& S. Cunningham (eds.), Visualisation in Teaching and Learning Mathematics, MAA Notes No. 19, 121-126.

8. Kaput, J., (1992). Technology and mathematics education. In D.A. Grouws (Ed.) Handbook of research on mathematics and teaching and learning. (pp. 515-556).

9. Morgan, A.T. (1990). A study of the difficulties experienced with mathematics by engineering students in higher education. International Journal of Mathematics Education in Science and Technology, 21(6), 975988.

10. Naidoo, R., (1996). Technikon students' understanding of differentiation. SAARMSE. 96 proceedings.

11. Orton, A., (1981). Understanding elementary calculus. Phd thesis. University of Leeds.

12. Papert, S. (1980). Mindstorms: Children, computers and powerful ideas. New York: Basic Books.

13. Orton, A., (1983). Students' Understanding of Differentiation, Educational Studies in Mathematics, 14, 235250.

14. Smith, D.A. \& Moore, L.C., (1991). Project Calc: An Integrated Laboratory Course. In C. Leinbach et al. (eds.), The Laboratory Approach to Teaching Calculus, MAA Notes, 81-92, Washington DC: MAA.

15. Tall, D. (1985a). Understanding the calculus. Mathematics Teaching, 110, $49-53$.

16. Tall, D (1985b). The gradient of a graph. Mathematics Teaching, 111, $48-52$.

17. Vithal,R., (2004). Mathematics, Devan, and project work. South African Journal of Education, 24, 225-232.

18. White, P., and Michael, M, (1996). Conceptual Knowledge in Introductory Calculus, Journal for Research in Mathematics Education,27(1), 79-95.

19. Zandieh, M.J., (2000). A Theoretical Framework for Analyzing Student Understanding of the Concept of Derivative CBMS Issues in Mathematics Education, 8, 103 -122. 
NOTES 